\title{
How Industry-University-Research Cooperation Influences Innovation Efficiency in China
}

\author{
Miao ZHANG \\ Northwest University, Xi'an, China \\ zhangmiao@nwu.edu.cn
}

\begin{abstract}
A provincial level balanced panel data set with 29 provinces and municipalities in China from 2009 to 2015 on the innovation production is used in this paper to analyze how industry-university-research cooperation influences innovation efficiency. Time-lag Stochastic Frontier Analysis models are applied and the results illustrates that cooperation between industries and universities takes a positive effect on innovation efficiency, the cooperation between industries and research institutions does not significantly influence innovation efficiency, and government funding for innovation has significant negative effect on innovation efficiency. The results also indicate that innovation efficiency in China in the sample years is not high; and is decreasing. The regional disparity of innovation efficiency is also obvious. Policy suggestions are presented in the conclusion of the paper.
\end{abstract}

Keywords: Innovation, Technical Efficiency, Industry-University-Research Cooperation.

\section{Introduction}

After more than 30 years of high speed GDP growth, China's GDP growth rate started decreasing from the first quarter of 2010. Some have placed the blame on the sluggish international economic environment; others refer to the fact that China's growth model has been changing from labor-intensive development to technology-intensive development, and innovation becomes an important driving factor. As the main bodies of innovation, industries, universities, and research institutes develop separately in a long time in China. The innovations of industries focus on new products intended to bring profits, while there always are lags between university innovations and market demands. The innovation of research institutes is in between. Less connection and cooperation among the three entities leads to the waste of research funding and high research costs for industries. Since 2006, the government of China has placed great emphasis on cooperation of industries, universities and research institutes. It is necessary to analyze how industry-university-research cooperation influences innovation efficiency.

Researchers have studied this topic from different aspects using different methods. Some studies analyze the factors that influence industry-university-research 
cooperation from the qualitative aspect. Salomon [9] considered openness as the indirect reason promoting research achievement transformation; Bin Guo et al [2] analyzed the influence of project properties and participants characteristics. Some studies measure the efficiency of cooperation using different quantitative methods. Junhong Bai [6] measured Chinese regional innovation efficiency using Stochastic Frontier Analysis (SFA). Tin Liu and Wei Sun [7] evaluated the industry-universityresearch cooperation efficiency for the manufacturing industry in Shaanxi province. In brief, researchers have analyzed how industry-university-research cooperation influences innovation efficiency from various points of view using different methods and different indicators, but with inconsistent conclusions. The methods are DEA (Data Envelopment Analysis) and SFA mainly. The DEA method does not require the information on the form of production function, thus it has less constraints, and it can deal with a multi-output model. But DEA ignores the existence of random error, which may lead to unreasonable results. In the SFA method, the error term is composed of two parts: one is the random error term, and the other one is an inefficient error term used to measure the producers' efficiency. The result obtained from SFA method is more reasonable and more explicable. But SFA method requires specifying the functional form and a single output or a single-output index which is aggregated from multiple outputs.

At this time in China's economic transition and innovation-driven development pattern, it is important to update the data and to analyze how industry-universityresearch cooperation influences innovation efficiency since 2005, the year when the "innovative development strategy" was proposed.

In consideration of data availability, policy time-lag and innovation time-lag, a panel data of 29 provinces and municipalities from 2009 to 2015 has been selected.

\section{Model Specification}

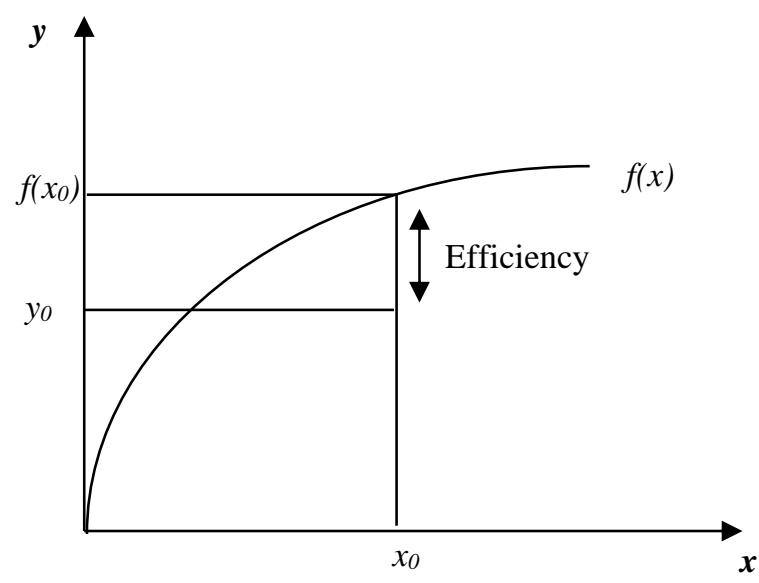

Fig. 1. Single input-single output production. 
In traditional production theory, all producers are assumed to attempt to obtain the optimum outputs, but in the real world, not all of them can achieve this result. The concept of frontier is used to describe the optimum result that producers want to and can produce given the technology level, shown as $f(x)$ in Figure 1. Figure 1 is an example of single input-single output production, where $x_{0}$ is the observed input, and $y_{0}$ represents the observed output, which is the actual output produced by $x_{0} . f\left(x_{0}\right)$ represents the maximum output which can be produced by $x_{0}$. Thus efficiency is defined as the ratio of actual output to potential output, which is the distance between the outputs, $y_{0} / f\left(x_{0}\right)$, and which is always smaller than or equal to 1 . The value of the distance is defined as the efficiency score. When it is equal to 1 , the producer is defined as efficient, when it is less than 1, the producer is defined as inefficient.

Due to the existence of stochastic effects, the SFA method, which is used in this paper, separates the distance into two parts: random error and inefficient error. The model is specified as:

$$
y_{i t}=f\left(x_{i t}, t\right) \exp \left(v_{i t}-u_{i t}\right)
$$

where $i$ indicates the individual province and $\mathrm{t}$ indicates the time period. $f\left(x_{i t}, t\right)$ indicates the maximum output (the frontier) which province $i$ could theoretically achieve in time $t$, while $y_{i t}$ is the real output of province $i$ in time $t$. The composed error term is used to measure the distance between maximum output and real output. $v_{i t}$ is the random error term, which captures all the random effects, such as the measurement error, the sampling error, and the specification error. $u_{i t}$ is the inefficient error term, which measures the provinces' efficiency. When the translog form is taken, equation 1 turns into equation 2

$$
\ln y_{i t}=\beta_{0}+\sum_{j} \beta_{j} \ln x_{j i t}+\frac{1}{2} \sum_{j} \sum_{i} \beta_{j l} \ln x_{j i t} \ln x_{l i t}+v_{i t}-u_{i t}
$$

The key point of the SFA model is to separate the inefficient error term from the composed error term. We use the model which considers the inefficient error term as follows:

$$
u_{i t}=\delta_{0}+z_{i t} \delta+w_{i t}
$$

where $u_{i t}$ is assumed to be independently distributed and obtained by truncation (at zero) of the normal distribution with mean $z_{i t} \delta$, and variance $\sigma^{2}$. $z_{i t}$ are the relevant influence factors which affect inefficiency. The sign of coefficient presents the influence of these factors. A positive sign indicates the negative influence on efficiency and a negative sign indicates the positive influence. 


\section{Data and Variables}

\subsection{Output Variable and Input Variables}

When we select the indicators, we follow the industry-leading principle, which means the aim of industry innovation is to make profits. The SFA method requires a single output on the left hand side of the equation. To measure innovation output, three primary indicators are used, the number of patents granted, the number of new products exploited and sales revenue of new products. With regard to patents, for reasons of secrecy, industries may not apply for patents on some innovations; or, industries may apply for patents to prevent competitors from making the same innovation, but this does not mean the innovation can be converted to meaningful production in a short period of time. Thus, the number of patents granted is not an ideal indicator. The number of new products exploited cannot reflect the economic values of innovation. Sales revenue of new products is used as the output variable because this can reflect the real benefit of innovation for industries

The input variables contain two aspects, labor and capital. Full-time equivalent of $R \& D$ personnel is used as the labor input. A capital stock variable is needed to measure the capital input, and the appropriate indicator is the intramural expenditure on $R \& D$, which has to be converted since it is a flow indicator. The method we use here is as follows:

$$
K_{i t}=(1-\delta) \times K_{i t-1}+E_{i t}
$$

where $K_{i t}$ is the R\&D capital stock of province $i$ in time $t, E_{i t}$ indicates the intramural expenditure on $\mathrm{R} \& \mathrm{D}$, and $\delta$ is the rate of depreciation, taking value 0.15 . The meaning of equation 4 is that the $R \& D$ capital stock is the depreciated capital stock plus the new added intramural expenditure. The estimation of the capital stock in the base year (2009) is shown as equation 5.

$$
k_{i 0}=E_{i 0} /(g+\delta)
$$

where $g$ is the geometric mean of the intramural expenditure on R\&D.

\subsection{Influence Factors and Assumptions}

The purpose of this paper is to detect the influence of industry-university-research cooperation on industry-leading innovation efficiency, thus the influence factors should reflect the degree of cooperation between industries and universities and between industries and research institutions.

We use the ratio of intramural expenditure on $R \& D$ in higher education raised from industries to the intramural expenditure on $R \& D$ in higher education to measure the degree of cooperation between industries and universities. As Figure 2 shows, the 
ratio is around $35 \%$ and is getting smaller in sample period. Theoretically, the cooperation between industries and universities should promote innovation activities.

Assumption 1: The cooperation between industries and universities has positive effects on innovation efficiency.

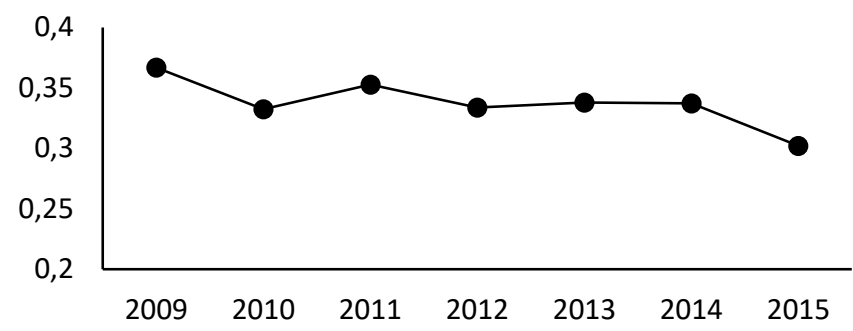

Fig. 2. The proportion of intramural expenditure on R\&D in universities from industries.

The proportion of intramural expenditure on $R \& D$ in research institutions from industries is used to measure the degree of cooperation between industries and research institutions. As Figure 3 illustrates, the proportion is around 3.1\% and the largest value is only $3.42 \%$. The relationship between industries and research institutions is cooperators and competitors. On one hand, the cooperation could save research cost and avoid repetitive research. On the other hand, research institutions in China does not only do researches, they also engage directly in the market as the competitor for industries. According to the low degree of cooperation, we have the second assumption:

Assumption 2: The cooperation between industries and research institutions has negative effects on innovation efficiency.

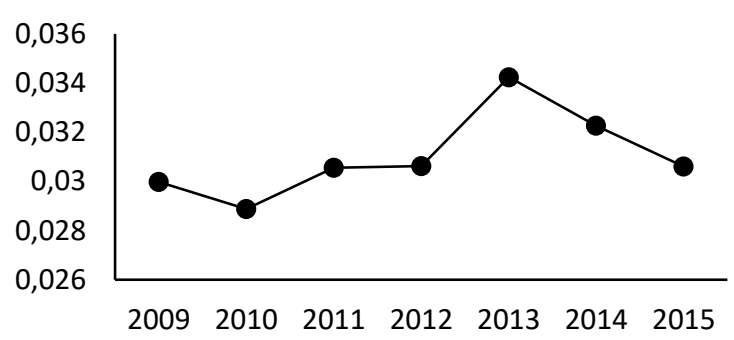

Fig. 3. The proportion of intramural expenditure on $R \& D$ in research institutions from industries.

In addition, government has a significant influence on regional innovation, through both policy support and the provision of funding. Therefore the proportion of regional intramural expenditure on $\mathrm{R} \& \mathrm{D}$ obtained from government is used as the control variable into the model to measure the degree of government participation in innovation. Figure 4 demonstrates the proportion of regional intramural expenditure 
on R\&D obtained from government and from industries. The primary source of intramural funds raised by industries, which is around $70 \%$, and it is increasing slightly each year. The proportion of intramural funds from government is around $22 \%$ and is decreasing slightly each year. But the proportion varies greatly in different regions, which is not shown in Figure 4. The average proportion of intramural funds raised by government is $8.30 \%$ in Guangdong province, but $55.12 \%$ in Beijing. Both provinces are important regions for innovation, so we make the third assumption:

Assumption 3: Government support has insignificant effects on innovation efficiency.

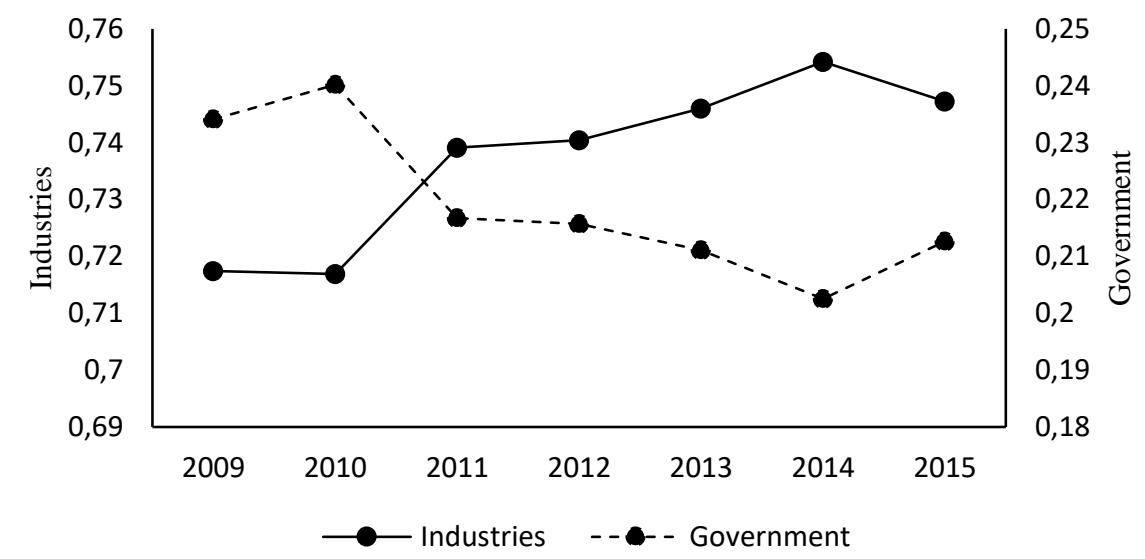

Fig. 4. The proportion of regional intramural expenditure on R\&D obtained from government and industries.

\subsection{Data Information}

A provincial level balanced panel data set with 29 provinces and municipalities from 2009 to 2015 in China on the innovation production is used in this paper, with 203 samples in total. Two regions, Tibet and Ningxia are discarded, because of the missing data and a limited number of innovation activities. All the data are from the China Statistic Yearbook, the Statistical Yearbook of Scientific and the Technological Activities of Industrial Enterprises, and the China Statistical Yearbook on Science and Technology. The base year is 2009 .

\section{$4 \quad$ Results and Discussion}

\subsection{A Discussion of Influence Factors}

One of the important features of innovation is the time-lag. The innovation activities themselves need time, the transformation from innovation to production needs time, and the transition from production to sales needs time, but due to competition, the 
time-lag will generally not be too long. Three models have been developed, a no timelag model (Model 1), a one-year time-lag model (Model 2), and a two-year time-lag model (Model 3). The results are shown in Table 1, where $\mathrm{L}$ is labor, $\mathrm{K}$ is capital stock, I-U indicates the cooperation between industries and universities, I-R indicates the cooperation between industries and research institutions, and $\mathrm{G}$ represents government participation in innovation.

Table 1. Estimation of Frontier and Influence Factors

\begin{tabular}{|c|c|c|c|}
\hline Variables & Model 1 & Model 2 & Model 3 \\
\hline \multicolumn{4}{|c|}{ Estimation of frontier } \\
\hline Constant & $\begin{array}{l}0.3446 * * * \\
(0.0709)\end{array}$ & $\begin{array}{l}0.5611 * * * \\
(0.0885)\end{array}$ & $\begin{array}{l}0.7080 * * * \\
(0.1276)\end{array}$ \\
\hline K & $\begin{array}{l}0.5178 * * * \\
(0.1198)\end{array}$ & $\begin{array}{l}0.3676 * * \\
(0.1474)\end{array}$ & $\begin{array}{l}0.4053 * * \\
(0.4089)\end{array}$ \\
\hline $\mathrm{L}$ & $\begin{array}{l}0.4039 * * * \\
(0.1175)\end{array}$ & $\begin{array}{l}0.5171 * * * \\
(0.1435)\end{array}$ & $\begin{array}{l}0.5240 * * \\
(0.2129)\end{array}$ \\
\hline KSQ & $\begin{array}{l}0.0050 \\
(0.2070)\end{array}$ & $\begin{array}{l}0.1010 \\
(0.2863)\end{array}$ & $\begin{array}{l}0.4410 \\
(0.3571)\end{array}$ \\
\hline LSQ & $\begin{array}{l}-0.2932 \\
(0.2053)\end{array}$ & $\begin{array}{l}-0.2293 \\
(0.2896)\end{array}$ & $\begin{array}{l}0.06757 \\
(0.3826)\end{array}$ \\
\hline KL & $\begin{array}{l}0.2603 \\
(0.4104)\end{array}$ & $\begin{array}{l}0.0970 \\
(0.5710)\end{array}$ & $\begin{array}{l}-0.5355 \\
(0.7281)\end{array}$ \\
\hline \multicolumn{4}{|c|}{ Estimation of influence factors } \\
\hline Constant & $\begin{array}{l}1.1027 \\
(1.6254)\end{array}$ & $\begin{array}{l}0.2951 \\
(0.5618)\end{array}$ & $\begin{array}{l}0.4133 \\
(0.7729)\end{array}$ \\
\hline $\mathrm{I}-\mathrm{U}$ & $\begin{array}{l}-0.8245 \\
(0.5386)\end{array}$ & $\begin{array}{l}-0.7619 * * \\
(0.3232)\end{array}$ & $\begin{array}{l}-0.8094 * * \\
(0.3340)\end{array}$ \\
\hline I-R & $\begin{array}{l}-0.0519 \\
(0.1023)\end{array}$ & $\begin{array}{l}0.0991 \\
(0.1078)\end{array}$ & $\begin{array}{l}0.1047 \\
(0.1237)\end{array}$ \\
\hline G & $\begin{array}{c}1.07575 \\
(0.7296)\end{array}$ & $\begin{array}{l}0.8558 * \\
(0.4361)\end{array}$ & $\begin{array}{l}0.7958 * * \\
(0.3847)\end{array}$ \\
\hline sigma-squared & $\begin{array}{l}1.1927 \\
(0.7745)\end{array}$ & $\begin{array}{l}0.9051 * * \\
(0.0053)\end{array}$ & $\begin{array}{l}0.7780 * * \\
(0.3378)\end{array}$ \\
\hline gamma & $\begin{array}{l}0.9401 * * * \\
(0.0365)\end{array}$ & $\begin{array}{l}0.9596 * * * \\
(0.0271)\end{array}$ & $\begin{array}{l}0.9315 * * \\
(0.0437)\end{array}$ \\
\hline Log value & -140.22 & -122.72 & -107.50 \\
\hline
\end{tabular}

The significance of gamma illustrates that innovation inefficiency exists significantly in the sample regions. In Model 2 and Model 3, the significance of sigma-squared illustrates that the variance of innovation inefficiency is significantly different from zero. Both labor and capital show significant positive impact on innovation production in the three models.

With respect to the influence factors, no significant effect of three influence factors is seen in Model 1. But the time-lag models, Model 2 and Model 3, present a different 
picture. The coefficient of the cooperation between industries and universities is significantly negative, which means that deeper cooperation between industries and universities has a positive influence on innovation efficiency. The result is the same as Assumption 1.

The coefficient of the cooperation between industries and research institutions is positive, which means that deeper cooperation between industries and research institutions has a negative influence on innovation efficiency, but insignificant. This is caused by the ambivalent relation between them, and the competition plays a more important role than cooperation. As we discuss above, the degree of cooperation between them is shallow. This result rejects Assumption 2.

The coefficient of the government participation in innovation is significantly positive, which means government support for innovation results in inefficiency. The government finding for innovation is focused on government oriented industries, but it may cause a crowding-out effect, resulting in decreasing investment from industries. Goolsbee [4] considers that government support increases the requirement of $R \& D$ personnel, which is inelastic. Therefore the result is that wages of $R \& D$ personnel increase but there is no effect on innovation production.

\subsection{The Discussion of Innovation Efficiency}

In this paper, a province is innovation efficient when it can obtain the maximum sales revenue of new products, otherwise, the province is inefficient. The higher the innovation efficiency score, the more efficient the province is. The highest value is 1 as discussed in section 2 .

The average national innovation efficiency scores in each year are shown in Figure 5. Models 1 and 2 show the same ascending trend before 2011 and all three models a descending trend afterwards. Chinese government attaching more importance to innovation does increase the quantity of innovation production, but our results show that the innovation efficiency is decreasing in later years.

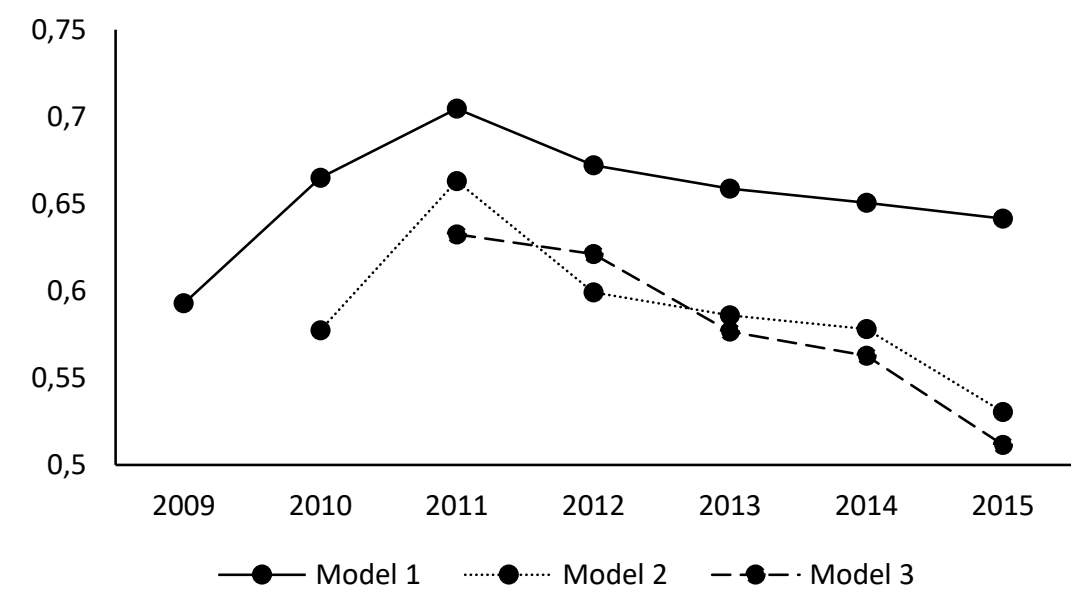

Fig. 5. The Average National Innovation Efficiency Scores in Each Year 
The average regional innovation efficiency ranks are shown in Table 2.Chongqing, Zhejiang and Hunan are Top 3 innovation efficient regions in all three models. The last three are Qinghai, Heilongjiang and Shanxi. In general, provinces and municipalities in East of China are the most innovation efficient, and provinces and municipalities in West of China are the most innovation inefficient. The rank is almost the same as economic development level of these regions.

Table 2. The Average Regional Innovation Efficiency Ranks.

\begin{tabular}{llcll}
\hline Region & Model 1 & Model 2 & Model 3 & Location \\
\hline Beijing & 11 & 12 & 12 & East \\
Tianjin & 5 & 4 & 4 & East \\
Hebei & 22 & 21 & 17 & East \\
Liaoning & 13 & 15 & 15 & East \\
Jilin & 8 & 10 & 14 & East \\
Heilongjiang & 28 & 28 & 28 & East \\
Shanghai & 6 & 6 & 6 & East \\
Jiangsu & 7 & 5 & 5 & East \\
Zhejiang & 2 & 2 & 3 & East \\
Fujian & 19 & 20 & 19 & East \\
Shandong & 9 & 7 & 7 & East \\
Guangdong & 10 & 9 & 10 & East \\
Hainan & 20 & 17 & 22 & East \\
Shanxi & 27 & 27 & 27 & Middle \\
Anhui & 12 & 11 & 9 & Middle \\
Jiangxi & 15 & 13 & 11 & Middle \\
Henan & 21 & 22 & 21 & Middle \\
Hubei & 14 & 14 & 13 & Middle \\
Hunan & 3 & 3 & 1 & Middle \\
Inner Mongolia & 25 & 25 & 24 & West \\
Guangxi & 4 & 8 & 8 & West \\
Chongqing & 1 & 1 & 2 & West \\
Sichuan & 17 & 18 & 18 & West \\
Guizhou & 24 & 24 & 23 & West \\
Yunnan & 23 & 23 & 25 & West \\
Shaanxi & 26 & 26 & 26 & West \\
Gansu & 18 & 19 & 20 & West \\
Qinghai & 29 & 29 & West \\
Xinjiang & 16 & 16 & West \\
\hline & & & & \\
\hline
\end{tabular}




\section{Conclusion}

This paper analyzes how industry-university-research cooperation influences innovation efficiency, by applying time-lag SFA models to a provincial level balanced panel data set with 29 provinces and municipalities from 2009 to 2015. The results illustrate that the innovation efficiency in China in the sample years is not high, and it is decreasing. The disparity of innovation efficiency among regions is obvious.

The cooperation between industries and universities takes a positive effect on innovation efficiency. But the degree of cooperation between them is not deep enough. This is partly because the university research does not match the requirements of industries and markets, and partly because the distribution of benefits is not reasonable. In order to enhance the cooperation between industries and universities, it will be necessary to develop various cooperation patterns to promote the transition from knowledge to production. Industries and universities can found company together where industries provide funds and universities provide technology. The government could also intervene by creating some intermediary agencies to build a bridge between industries and universities. In addition, some policies should be carried out to balance the benefit distribution, such as allowing university researchers to attend the research directly within industries and giving them more benefit.

The cooperation between industries and research institutions does not has a significant influence on innovation efficiency. This is because research institutions often engage directly in the market as the competitor for industries, but there is almost no cooperation between them. To a certain degree, this is a waste of scientific and technological research resources. Therefore, it would be better to make more rational distribution of research domains, avoiding competition and stimulating cooperation.

Government funding for innovation does not have a positive effect on innovation efficiency, which is not as we expected. What the government should do is to guide the layout of industries but not to attend the innovation activity directly.

Since the level of economic development varies among different provinces and municipalities, and the distributions of universities and research institutions is various, it is necessary to analyze the influences on innovation efficiency by industryuniversity-research cooperation in regions which have more universities and research institutions in the future studies.

Acknowledgements. The paper has been funded by Education Department of Shaanxi Provincial Government (with the project title "The comparison of Shaanxi Innovation Efficiency Influenced by Industry-University-Research Cooperation ") The author is grateful for helpful comments from three reviewers and my colleague Paul. 


\section{References}

1. Junhong, B., Keshen, J., Jing L.: The Estimation of China's Regional Innovation Efficiency by SFA Model. Management world. 10(October 2009), 51-61 (2009).

2. Battese, G. E., Coelli, T.J.: A Model for Technical Inefficiency Effects in a Stochastic Frontier Production Function for Panel Data. Empirical Economics 20(2), 325-332. (1995).

3. Farrell, M. J.: The Measurement of Productive Efficiency. Journal of the Royal Statistical Society Series A General 120(3), 253-290 (1957).

4. Goolsbee, A.: Does Government R\&D Policy Mainly Benefit Scientists and Engineers. American Economic Review 31(6), 298-302 (1998).

5. Greene, W.H. Fixed and Random Effects in Stochastic Frontier Models. Journal of Productivity Analysis 23(1/January), 7-32 (2005).

6. Bin, G., Zhiyu, X., Huifang, W.: The Influence Factors of Industry-University-Research Cooperation and Empirical Analysis. Studies in Science of Science. 1(Supplementary), 140-147 (2003).

7. Minting, L., Wei, S.: The study on Industry-University-Research Cooperation Efficiency using DEA-Applied to Manufacturing Industry in Shaanxi Province Science of Science and Management of S.\& T. 32(3), 11-15 (2011).

8. Pitt, M., Lee, L. F.: The Measurement and Sources of Technical Inefficiency in the Indonesian Weaving Industry. Journal of Development Economics, 9(August 1981), 43-64 (1981).

9. Salomon, R: Does Knowledge Spill to Leaders or Laggards? Exploring Industry Heterogeneity in Learning by exporting. Journal of International Business Studies 39(January 2008), 132-150 (2008).

10. Schmidt, P., Sickles, R., G.: Production frontiers and Panel Data. Journal of Business and Economic Statistics 2(October 1984), 367-374 (1984). 